\title{
Vena cava superior syndrome in the children with mediastinal tumors: Single-center experience
}

\author{
(D) Alper Ozcan, ${ }^{1}$ (1) Ekrem Unal, ${ }^{1}$ () Musa Karakukcu, ${ }^{1}$ (i) Abdulhakim Coskun, ${ }^{2}$ () Mehmet Akif Ozdemir, ${ }^{1}$ \\ D Turkan Patiroglu ${ }^{1}$ \\ ${ }^{1}$ Division of Pediatric Hematology-Oncology, Department of Pediatrics, Erciyes University Faculty of Medicine, Kayseri, Turkey \\ ${ }^{2}$ Division of Pediatric Radiology, Department of Radiology, Erciyes University Faculty of Medicine, Kayseri, Turkey
}

\begin{abstract}
OBJECTIVE: Vena cava superior syndrome comprises various symptoms of compression of vena cava superior. The results of increased venous pressure in the upper body may cause edema of the head and neck associated with cyanosis, plethora and distended subcutaneous vessels. Vena cava superior syndrome is rare in childhood. Therefore, we planned this retrospective study.

METHODS: The retrospective study was carried out on the children with mediastinal tumors in the Department of Pediatric Hematology-oncology, Erciyes University Faculty of Medicine, Kayseri,Turkey, from January 2010 to December 2017. Diagnostic procedures included hematological investigations, chestradiography, thoracic computed tomography, echocardiography and lymph node or mediastinal biopsy.

RESULTS: In this study, 19 (five were female) of 41 patients with mediastinal tumors had Vena cava superior syndrome. Diagnosis included Hodgkin's lymphoma in seven (37\%), non-Hodgkin's lymphoma in six (32\%), acute T- lymphoblastic leukemia in four (21\%), neuroblastoma and anaplastic round cell sarcoma in one each respectively. All of the 19 patients' facial swelling, venous distention and mediastinal widening. All patients received intravenous corticosteroids $(0.6 \mathrm{mg} / \mathrm{kg}$ dexamethasone). Furthermore, the patient with anaplastic round cell sarcoma received emergency radiotherapy. No patients died because of Vena cava superior syndrome.
\end{abstract}

CONCLUSION: Vena cava superior syndrome is a medical emergency that requiresurgent treatment. Vena cava superior syndrome studies in children are rare. In this retrospective study, we found that the most common cause of Vena cava superior syndrome was Hodgkin's lymphoma different from literature.

Keywords: Child; emergency treatment; mediastinal tumor; vena cava superior syndrome.

Cite this article as: Ozcan A, Unal E, Karakukcu M, Coskun A, Ozdemir MA, Patiroglu T. Vena cava superior syndrome in the children with mediastinal tumors: Single-center experience. North Clin Istanb 2020;7(3):255-259.

$\mathrm{V}$ ena cava superior syndrome (VCSS) is a clinical picture emerging with the impairment of blood flow and venous return to the heart as a result of the obstruction of superior vena cava. Depending on the acutely developing obstruction of blood flow, respi- ratory distress and neurologic symptoms arise [1]. VCSS was first described by William Hunter in 1757 in a patient with syphilitic aorta aneurism. Vena cava syndrome in children develops as a result of external pressure depending on the oncologic problems. VCSS

This articler was published in the Abstract Book in the 23 ${ }^{\text {rd }}$ Congress of EHA Stockholm from June 14-17, 2018 Final Abstract Code: PB1650

Received: January 07, 2019 Accepted: August 01, 2019 Online: April 09, 2020

Correspondence: Dr. Alper OZCAN. Erciyes Universitesi Tip Fakultesi, Cocuk Sagligi ve Hastaliklari Anabilim Dali, Cocuk Hematoloji ve Onkoloji Bilim Dali, 38039, Melikgazi, Kayseri, Turkey.

Tel: +90 3522076666 - 25475 e-mail: dralperozcan@hotmail.com

(c) Copyright 2020 by Istanbul Provincial Directorate of Health - Available online at www.northclinist.com 
may also ariset from intrinsic causes associated with the treatment of congenital cardiac defects or with thrombosis developing in connection with the central venous catheters. Vena cava superior syndrome gives rise to complications that cause morbidity and mortality to increase morbidity and mortality [2, 3]. Although there are many unanswered questions about VCSS in the pediatric age group, the number of studies on its clinical findings is quite low. Therefore, presented in this study are the findings related to VCSS in pediatric patients with mediastinal tumor followed-up in our department.

\section{MATERIALS AND METHODS}

In the present study, the records of the patients diagnosed with mediastinal tumor and those with accompanying VCSS clinic in the Pediatric Hematology Oncology Department of the Erciyes University Faculty of Medicine from 2010 to 2017 were studied retrospectively. The data concerning the patients diagnosed with vena cava superior syndrome, such as their demographic features, clinical findings, radiological examinations, diagnostic methods used, pathological diagnoses, the medical and surgical treatments they had received, and their prognoses, wererecorded. In patients with mediastinal tumors VCSS diagnosis was made using hematologic and biochemical analyses, tumor markers, bone marrow aspiration and biopsy, chest graph, echo-cardiograph, and assessment of mediestinal and lymph node biopsies. The consent for this study was obtained with the resolution of Erciyes University Faculty of Medicine Ethic Committee dated December 22, 1017 and numbered 2017/593. Informed written consent was taken from the parents of all the children included in this study.

\section{Statistical Analyses}

SPSS 20,0 for Windows program was used for the statistical analyses of the data in this study. Whether the data in statistical analyses suit normal distribution or not were determined using 'Shapiro-Wilk' test.

\section{RESULTS}

Of the 41 patients diagnosed to have mediastinal tumor, 19 (46.3\%) were detected to have VCSS symptoms. Of the patients with vena cava superior syndrome, 14 (74\%) of them were male, while five (26\%) of them were male, and their mean age was 8.57 (the youngest was 1 and the oldest was 17 years old). Of the 41 patients with mediastinal tumor detected, 18 (44\%) were diagnosed to have Hodgkin Lymphoma (HL), 12 (29\%) neuroblastoma, sixpatients (15\%) T-cell Non-Hodgkin Lymphoma (NHL), four patients (10\%) T-cell acute lymphoblastic leukemia (ALL) andone patient (2\%) anaplastic roundcell sarcoma. Of the patients with vena cava superior syndrome clinic; however, seven patients $(37 \%)$ were diagnosed with HL, six patients (32\%) with NHL, 4 (21\%) with T-ALL, 1 (5\%) with neuroblastoma, andone patient $(5 \%)$ anaplastic round cell sarcoma. Of the HL patients with VCSS, four patients (57\%) had HL of nodular sclerosing type, three patients (43\%) of mixed cellular type. All the patients with vena cava superior syndrome were detected to have T-cell NHL. In all of the 19 patients with the diagnosis of vena cava superior syndrome, swelling in the face, prominence of superficial veins, mediastinal expansion were most frequently detected clinical findings, and coughing, dyspnea, orthopnea, wheezing respiration, and headache were other signs detected. Radiological examination of the patients with vena cava superior syndrome revealed mediastinal expansion in all of them, and pleural effusion was detected in two patients (Table 1). Two patients with pleural had NHL. These patients underwent thoracentesis for cytologic and flow cytometry, and one of them had an indwelling chest tube installed.

Eight patients underwent diagnostic mediastinal biopsy, eight patients lymph node biopsy, eight patients bone-marrow aspiration, and 18 patients underwent the examination of bone-marrow aspiration. All the patients received intravenous corticosteroid (dexamethasone $6 \mathrm{mg} / \mathrm{m}^{2} /$ day) before diagnostic proceedings. It was observed that the respiratory distress was relieved and swellings on the face reversed within 48 hours following the start of corticosteroid treatment. The patient with and cava superior syndrome clinic diagnosed with anaplastic round cell sarcoma was given exigent radiotherapy before diagnostic proceedings.

The patients diagnosed to have Hodgkin Lymphoma received COPP/ABVD, those with NHL received Berlin-Frankfurt-Münster protocol, those with T-cell ALL (ALLIC Berlin-Frankfurt-Münster 2009), 1 patient diagnosed to have neuroblastoma received Turkish Pediatric Oncology Group 2009, anaplastic round cell sarcoma received vinkristin, cyclophosphamide etoposide, therapy and radiotherapy. In the current study VCSSrelated mortality did not occur. 
TABLE 1. Demographic, pathological and clinical assessment of the patients diagnosedwithvena cava superior syndrome

\begin{tabular}{lcc} 
& $\mathrm{n}$ & $\%$ \\
\hline Age 8.57 years (lowest 1-highest 17) & & \\
Sex & 5 & 26 \\
$\quad$ Female & 14 & 74 \\
$\quad$ Male & & \\
Mediastinal tumor types developing VCSS & 37 \\
$\quad$ Hodgkin Lymphoma & 4 & 57 \\
$\quad$ Nodular sclerosing type & 3 & 43 \\
$\quad$ Mixed cellular type & 6 & 32 \\
Non-Hodgkin Lymphoma & 6 & 100 \\
$\quad$ T-cell NHL & 4 & 21 \\
Acute lymphoblastic leukemia & 4 & 100 \\
$\quad$ T-cell ALL & 1 & 5 \\
Neuroblastoma & 1 & 5 \\
Anaplastic large cell sarcoma & & \\
Clinical findings & 19 & 100 \\
$\quad$ Swelling in the face & 19 & 100 \\
Prominence in superficial veins & 19 & 100 \\
Cough & 10 & 53 \\
Dyspnea & 8 & 42 \\
Wheezing & 8 & 42 \\
Orthopneic respiration & 5 & 26 \\
Cyanosis & 4 & 21 \\
Agitation/impairment of consciousness & 3 & 16 \\
Headache & & \\
Radiological findings & 19 & 100 \\
Mediastinal expansion & 2 & 11 \\
Pleural effusion & - & - \\
$\quad$ Mortality & & \\
\hline
\end{tabular}

VCSS: Vena Cava superior syndrome; HL: Hodgkin Lymphoma; NHL: Non-Hodgkin's Lymphoma: ALL: Acute lymphoblastic leukemia.

\section{DISCUSSION}

The clinical signs and symptoms that arise from the presence of obstruction in draining blood to the atrium through vena cava superior are called VCSS. Vena cava is responsible for the venous drainage of head, neck, arms and upper part of the chest. The internal pressure of vena cava in children is low, and its walls are thin. Therefore, they are rather susceptible to pressure. The pressure of vena cava may be asymptomatic, but it may manifest itself with light symptoms. Unexpected sudden deaths may also be encountered. Therefore, in less than $1 \%$ of the children with cancer, VCSS signs, such
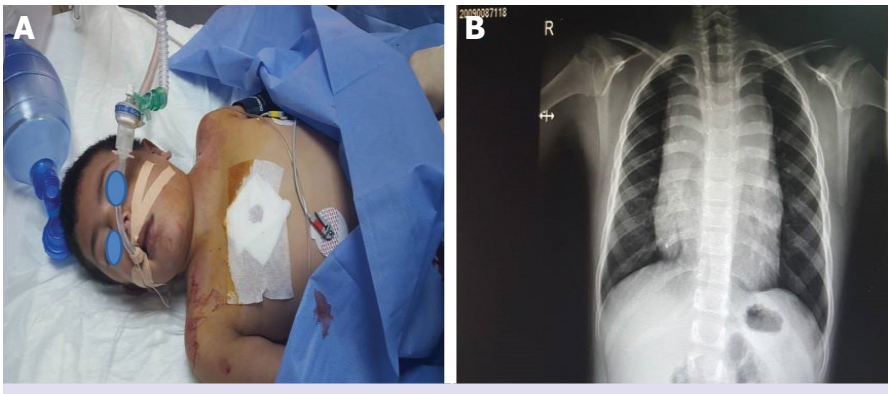

FIGURE 1. (A) Our patients diagnosed with lymphoblastic leukemia. (B) The chest radiography and the mediastinal expansion observed of our patients diagnosed to have Tcell lymphoblastic leukemia.

as dyspnea, coughing stridor, dysphagia, jugular venous distention, edema, cyanosis, and the need for intensive care, particularly more in young children, may arise $[1,2$, 4]. In our patients the superficial veins' becoming prominent, swelling in the face due to the impairment of venous return were the most frequently encountered signs. Dyspnea, orthopneic and coughing were other frequent clinical signs we detected (Fig. 1A, B). Arya et al. [4] have reported that coughing and respiratory distress are the first signs of VCSS. Gupta et al. [5], however, have emphasized that the most frequent signs are superficial veins becoming more noticeable and swelling in the face, similar to our patients' signs. Particularly dyspnea, distention of superficial veins, and swelling in the face signs should alert us.

In our study, the most frequent cause of VCSS is lymphoma. However, in our study it has been detected that, contrary to the literature, lymphoma which most frequently causes VCSS is not NHL but HL. VCSS was seen most frequently in nodular sclerosing lymphoma, a subtype of Hodgkin Lymphoma [6]. In our study, the most common cause of VCSS after Hodgkin Lymphoma and non-Hodgkin Lymphoma was T-cell lymphoblastic leukemia, similar to other studies. Arya et al. [4], however,have reported that the most common cause of VKSS is unicellular leukemia. Issa et al. [7], in their series of 10 cases, reported that NHL was detected in five, and HL in three of the eight patients with VCSS, and five of these patients were reported to NHL, and three to be HL.

Whole blood count, peripheral smear examination, erythrocytes sedimentation rate, detection of serum lactate dehydrogenase, uric acid, creatinin, calcium, phosphor, and potassium levels should be given priority. AFP and $\beta$-HCG levels for the diagnosis of germ cell tumors, and serum neuron-specific enolase levels for the diagno- 

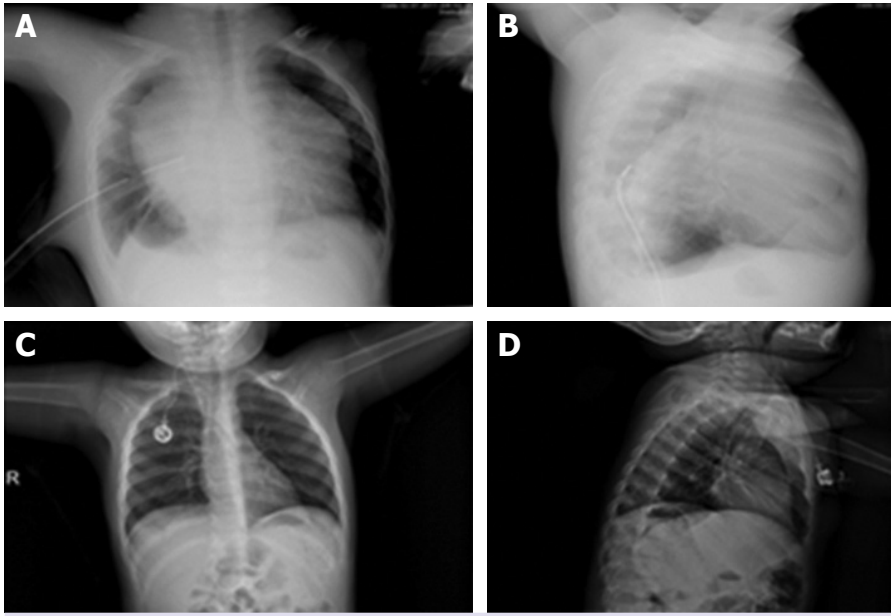

FIGURE 2. (A, B) The chest radiography taken at the time of diagnosis of our patients who were diagnosed with NonHodgkin Lymphoma. (C, D) The response to chemotherapy with dexamethasone of our patients diagnosed with nonHodgkin's Lymphoma.

sis of neuroblastoma should be measured. Bone-marrow aspiration and biopsy can be carried out for the patients suspected of leukemia, lymphoma, and neuroblastoma [8]. Chest graph to be able to see mediastinal expansion, and computerized chest graph, and/or chest MR imaging to be able to detect the character, and extension of tumor, and finally, thrombus and pleural fluid, if any, can be carried out. In addition, chest graphs have an exceptional place in monitoring therapeutic response. Owing to its being simple and cost-effective, chest graphs have been used in assessing their response to treatment (Fig. $2 \mathrm{~A}-\mathrm{C}$ ). Tissue diagnosis can be made with accompanying thoracotomy or thoracostomy and mediastinoscopy. For diagnosis, primarily peripheral smear, bone-marrow aspiration and biopsy, pleural fluid, or examination of pericardial fluid and removal of a peripheral lymph node should be tried $[1,8,9]$.

Vena cava superior syndrome is an emergent condition, but the diagnostic proceedings intended for quick diagnosis and premedication may cause death. In addition to physical examination, hematologic and radiologic analyses and bone marrow aspiration/biopsy under local anesthesia can be more reliable. Since thoracotomy and mediastinal biopsies require general anesthesia, cardiovascular collapse and respiratory tract obstruction may occur, which, in turn, may lead to mortality. In the case of a delayed diagnosis, treatment should not be delayed. The anesthesia proceedings of the patients with vena cava superior syndrome carry high mortality and morbidity
[10]. In none of the patients included in the study was complication detected during the diagnostic proceedings.

To be able to help venous drainage and reduce edema in patients with vena cava superior syndrome, the appropriate head position should be secured and oxygenation should be provided. If tumor lysis syndromes not accompanying, large quantities of liquid should not be given. In the presence of tumor lysis syndrome, allopurinol and recombinant urate oxidase can be administered (rasburicase). To reduce the hydrostatic pressure, all the fluids should be administered from lower extremities [11-13].

Since the most frequent cause of vena cava superior syndrome in the pediatric period is leukemia/lymphoma, the medication suggested in the first place is corticosteroids. Corticosteroids reduce tumor load, airway pressure and edema. Dexamethasone $\left(4-6 \mathrm{mg} / \mathrm{m}^{2} /\right.$ day) or hydrocortisone $(5 \mathrm{mg} / \mathrm{kg} /$ dose fourtimes per day) are the corticosteroid derivatives suggested $[12,14]$. All of our patients were administered head elevation, oxygenation and fluid in limited quantity, and as the first step, dexamethasone therapy $\left(6 \mathrm{mg} / \mathrm{m}^{2} /\right.$ day $)$ was started followed by diagnostic procedures, as treating a life-threatening condition is more important than treating a disease [15].

In cases where corticosteroid therapy alone does not provide clinical relief, vincristine, alkylating agents, or anthracyclines can also be added to the therapy $[3,12]$. Only in one of our patients vincristine $\left(1.5 \mathrm{mg} / \mathrm{m}^{2}\right)$ and dexamethasone $\left(6 \mathrm{mg} / \mathrm{m}^{2} /\right.$ day $)$ were used in combination. Anticoagulation with heparin of low molecular weight can be provided as a caution against potential tumor pressure, and by extension, thrombosis [16]. None of our patients in the study required anti-coagulant therapy.

Another emergency that arises during the therapy of vena cava superior syndrome is respiratory tract edema resulting from radiation. Radiotherapy, which is used therapeutically, may occasionally cause difficulty in tissue diagnosis [17]. Only one of our patients (the one diagnosed with anaplastic round cell sarcoma) received exigent radiotherapy owing to respiratory distress and cyanosis.

In the treatment of vena cava superior syndrome, endovascular stent applications are also possible. However, none of our patients was subjected to this practice [18].

The limitation of our study is that it is mono-centered and that the patients have been included in the study retrospectively. Although the number of cases is high, there are not sufficient multi-centered, broad-based studies on VCSS in the pediatric period. 


\section{Conclusion}

Pediatric mediastinal masses and their accompanying VCSS have a broad clinic. History, physical examination, laboratory analyses, and radiologic assessments should be performed in an appropriate order. In case of biopsy or surgical choice, anesthetic risks should be considered. When diagnosed vena cava superior syndrome clinic should be treated urgently owing to its mortality and morbidity.

Ethics Committee Approval: Erciyes University Faculty of Medicine Ethical Committee granted approval for this study (date: 22.12.2017, number 2017/593).

Conflict of Interest: No conflict of interest was declared by the authors.

Financial Disclosure: The authors declared that this study has received no financial support.

Authorship Contributions: Concept - TP, MAO; Design - AO; Supervision - TP, AO; Materials - MAO; Data collection and/or processing - $\mathrm{MK}, \mathrm{AC}$; Analysis and/or interpretation - $\mathrm{AO}$, EU; Literature review - EU, AO; Writing - AO; Critical review - TP, MAO, MK.

\section{REFERENCES}

1. Nossair F, Schoettler P, Starr J, Chan AKC, Kirov I, Paes B, Mahajerin A. Pediatric superior vena cava syndrome: An evidencebased systematic review of the literature. Pediatr Blood Cancer 2018;65:e27225. [CrossRerf]

2. Rizvi I, Zaman S, Zaidi N, Ashraf SM, Kumar A, Gupta A, et al. Superior vena cava syndrome caused by Hodgkin's lymphoma in an adolescent girl. BMJ Case Rep 2012;2012:bcr0120125487. [CrossRerf]

3. Zimmerman S, Davis M. Rapid Fire: Superior Vena Cava Syndrome. Emerg Med Clin North Am 2018;36:577-84. [CrossRerf]

4. Arya LS, Narain S, Tomar S, Thavaraj V, Dawar R, Bhargawa M. Supe- rior vena cava syndrome. Indian J Pediatr 2002;69:293-7. [CrossRerf]

5. Gupta V, Ambati SR, Pant P, Bhatia B. Superior vena cava syndrome in children. Indian J Hematol Blood Transfus 2008;24:28-30. [CrossRerf]

6. Bellefqih S, Khalil J, Mezouri I, Afff M, Elmajjaoui S, Kebdani T, et al. Superior vena cava syndrome with malignant causes. [Article in French]. Rev Pneumol Clin 2014;70:343-52. [CrossRerf]

7. Issa PY, Brihi ER, Janin Y, Slim MS. Superior vena cava syndrome in childhood: report of ten cases and review of the literature. Pediatrics 1983;71:337-41.

8. Güler S, Demirkaya M, Sevinir B. Approach to Childhood Mediastinal Mass. Guncel Pediatri 2016;14:30-6. [CrossRerf]

9. McCarten KM, Metzger ML, Drachtman RA, Pei Q, Friedman DL, Schwartz CL, et al. Significance of pleural effusion at diagnosis in pediatric Hodgkin lymphoma: a report from Children's Oncology Group protocol AHOD0031. Pediatr Radiol 2018;48:1736-44. [CrossRerf]

10. Chaudhary K, Gupta A, Wadhawan S, Jain D, Bhadoria P. Anesthetic management of superior vena cava syndrome due to anterior mediastinal mass. J Anaesthesiol Clin Pharmacol 2012;28:242-6. [CrossRerf]

11. Cheng S. Superior vena cava syndrome: a contemporary review of a historic disease. Cardiol Rev 2009;17:16-23. [CrossRerf]

12. Jain R, Bansal D, Marwaha RK, Singhi S. Superior mediastinal syndrome: emergency management. Indian J Pediatr 2013;80:55-9.

13. Mattu A. Hematologic and Oncologic Emergencies. Emerg Med Clin North Am 2018;36:xiii-xiv. [CrossRerf]

14. Bochenek-Cibor J, Püsküllüoğlu M, Zygulska A. Oncological emergencies: superior vena cava syndrome. Przegl Lek 2014;71:697-9.

15. Stanková Y, Vasutová I, Skricková J. Superior vena cava syndrome (definition, aetiology, physiology, symptoms, diagnosis and treatment. [Article in Czech]. Vnitr Lek 2007;53:1211-4.

16. Herrak L, Amangar N, El Ftouh M, El Fassy Fihry MT. Thrombosis of the superior vena cava revealing a protein $\mathrm{S}$ deficiency. [Article in French]. Rev Pneumol Clin. 2012;68:364-6. [CrossRerf]

17. Talapatra K, Panda S, Goyle S, Bhadra K, Mistry R. Superior vena cava syndrome: A radiation oncologist's perspective. J Cancer Res Ther 2016;12:515-9. [CrossRerf]

18. Büstgens FA, Loose R, Ficker JH, Wucherer M, Uder M, Adamus R. Stent Implantation for Superior Vena Cava Syndrome of Malignant Cause. Rofo 2017;189(5):423-30. [CrossRerf] 